\title{
Enhancement of Tall Buildings Under the Wind Load
}

\author{
Mohammad Javed ${ }^{1}$, Satish Kumar ${ }^{2}$, \\ ${ }^{1}$ M.Tech Scholar Structural Engineering Department of Civil Engineering, Rama University Kanpur India \\ Asst. Proff. Department of Civil Engineering, Rama University Kanpur India
}

\begin{abstract}
In developing countries, population are rising very rapidly has forced to emphasis on design and construction of multilevel tall buildings. Civil Engineering is a fundamental element of our society. The tall structures of buildings are designed to persist the rigid loads. However, they may be exposed to dynamic load such as wind effect, cyclone, earthquakes etc. The impact of wind loads are to consider for the design of high rise building as there are many failures of structures have appeared in India due to wind. Wind-induced vibrations in structures increases the importance of structural design as the use of high-strength, lightweight materials, longer floor spans, and more flexible framing systems are used, results in structures that are more prone to vibrations. From the present study it can be concluded that wind effects are significant compared to gravity effect. This paper discusses these challenges and the engineering solutions that they require to successfully design a tall building which is not only stable, safe and strong under wind loads but also performs excellently providing usable and highly functional design structure.
\end{abstract}

Key words: High- rise building, Wind effects.

\section{INTRODUCTION}

Due to rapid increase in population, the land area around the world becoming more congested day by day that increase the demand of taller buildings. It requires expert engineering designs to cater the challenging modern construction market. Wind is created by the difference in pressure on the surface of the earth. It varies with time and space. Due to the unpredictable nature of wind, it is necessary to design the tall structures by considering the critical effects of wind on the structure. Taller the building the more sensitive it is to wind loads as compared to earthquake loads Designers are concerned about choosing structural systems that can carry lateral loads as well as ascertained serviceability and occupant comfort requirements. These complexities of wind and the loads it applies on structures should be kept in mind when designing a tall building. High-rise buildings may be considered as a symbol of development and civilization. From structural point of view, these are buildings of which height will be affected by lateral forces resulting from earthquake and wind loads to the extent that such forces will play a major role in the design process. High-rise building construction is a challenging project undertaken by experts and engineers. To build a tall building, one should think of a construction project whose design depends totally on analytical analysis and scaled modeling.
The structural engineer should ensure that the structure should be safe and serviceable during its anticipated life even if it is subjected to wind loads. Wind forms the predominant source of loads, in tall free standing structures The knowledge of wind loading on a single tall building or on a group of tall buildings is essential for their economic design. It is the task of the engineer to ensure that the performance of structures subjected to the action of wind will be adequate during their anticipated life from the standpoint The purpose of structural control in civil engineering structures is to reduce vibrations produced by external stressors such as earthquake and wind loads, by different techniques such as modifying stiffness, mass, damping, or shape. Structural control methods are typically classified as active, passive, and semi-active techniques.

\section{WIND LOADS ON MULTILEVEL BUILDINGS}

The wind load is the most important factor that determines the design of all multilevel buildings. An important problem associated with wind induced motion of buildings is concerned with human response to vibration and perception of motion. The complexities of wind loading should be kept in mind when applying a design document. These factors have increased the importance of wind in design consideration. The wind is the most powerful force that affecting on tall or high building. Under the action of heavy wind flow, structures experience most common aerodynamic force inducing on high rise building.1) Along Wind Effect 2) Across Wind Effect. Large wind pressure fluctuations occur on the surface of a building due to the above mentioned characteristics. As a result, large aerodynamic loads are imposed on the structural system and intense localized fluctuating forces act on the facades.

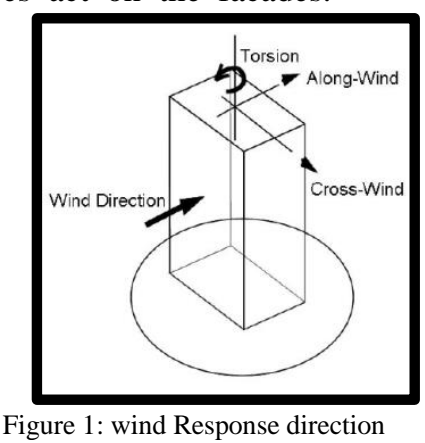

For estimations of the overall stability of a structure and of the local pressure distribution on the building, knowledge of the maximum steady or time averaged wind loads is 
usually sufficient

Wind approaching a building is a complex phenomenon where the flow pattern generated around a building is complicated by the distortion of the mean flow, the flow separation, the vortex formation, and the wake development.

\section{WIND SPEED}

At nice heights higher than the surface of the world, where resistance effects are negligible, air movements are driven by pressure gradients within the atmosphere, which successively are the physics consequences of variable star heating of the world. This upper level wind speed is thought because the gradient winds speed.

The basic wind speed $\left(\mathrm{V}_{\mathrm{z}}\right)$ for any site is given by

Where,

$$
\mathrm{V}_{\mathrm{z}}=\mathrm{V}_{\mathrm{b}} \cdot \mathrm{k}_{1} \cdot \mathrm{k}_{2} \mathrm{k}_{3}
$$

$\mathrm{V}_{\mathrm{Z}}=$ hourly mean wind speed in $\mathrm{m} / \mathrm{s}$, at height $\mathrm{z}$

$\mathrm{V}_{\mathrm{b}}=$ regional basic wind speed in $\mathrm{m} / \mathrm{s}$

$\mathrm{k}_{1}=$ probability factor (risk coefficient)

$\mathrm{k}_{2}=$ Terrain and height factor

$\mathrm{k}_{3}=$ topography factor

\section{DESIGN WIND PRESSURE}

The design wind pressure at any height above mean level shall be obtained by the Following relationship between wind pressure and wind velocity:

Where,

$$
\mathrm{P}_{\mathrm{z}}=0.6 \mathrm{~V}_{\mathrm{z}}^{2}
$$

$\mathrm{P}_{\mathrm{z}}=$ Design wind pressure in $\mathrm{N} / \mathrm{m} 2$ at height ' $\mathrm{z}$ ' $\mathrm{m}$

$\mathrm{V}_{\mathrm{z}}=$ design wind velocity in $\mathrm{m}$

Force Based (Limit State) Design Criteria

for Wind

3.1 Wind Loads

Force Based (Limit State) Design Criteria

for Wind

3.1 Wind Loads

Force Based (Limit State) Design Criteria

for Wind

3.1 Wind Loads

FORCE BASED DESIGN CRITERIA FOR WIND LOAD

In terms of designing a tall building for lateral wind loads using force based methods the following design

criteria need to be satisfied;

- Stability against overturning, uplift or sliding of the structure as a whole.

- Strength of the structural components of the building required to be withstood without failure during the life of the structure.

- Serviceability where inter-story and overall deflections are within acceptable limits. Control of deflection and drift is imperative for tall buildings with the view to limiting damage and cracking to non-structural members such as facade, internal partitions and ceiling.

\section{WIND ACCELERATION}

An additional criterion that requires careful consideration design to control accelerations when subjected to wind loads under serviceability conditions. Wind accelerations are calculated for wind speeds with very low return periods (e.g. 1, 5 or 10 years depending on the availability of wind speed data for the considered region). Wind accelerations too will need to be evaluated as both along-wind and crosswind responses. It requires an expert judgment on how the parameters are to be considered where the building deviates from such rectangular shapes and typical aspect ratios.

\section{DESIGN WIND LOAD}

The characteristics of wind pressures on a structure square measure an operate of the characteristics of the approaching wind, the pure mathematics of the structure under thought, and therefore the pure mathematics and proximity of the structures upwind. The pressures don't seem to be steady, however extremely unsteady, partially as a results of the gustiness of the wind, however conjointly due to native vortex shedding at the perimeters of the structures themselves. The unsteady pressures may end up in fatigue harm to structures, and in dynamic excitation, if the structure happens to be dynamically wind sensitive. The pressures also are not uniformly distributed over the surface of the structure, but vary with position. The complexities of wind loading ought to be unbroken in mind once applying a style document. Because of the numerous uncertainties concerned, the utmost wind masses knowledgeable about by a structure throughout its lifetime, could vary wide from those assumed in design. Thus, failure or non-failure of a structure in a wind storm can't essentially be taken as Associate in Nursing indication of the nonconservativeness, or conservativeness, of the Wind Loading commonplace. The Standards don't apply to buildings or structures that square measure of bizarre form or location. Wind loading governs the look of some kinds of structures such as tall buildings and slender towers. It often becomes enticing to form use of experimental wind tunnel information in situ of the coefficients given in the Wind Loading Code for these structures.

\section{TYPES OF WIND DESIGN}

Typically for wind sensitive structures three basic wind effects need to be considered.

- Environmental wind studies - investigate the wind effects on the surrounding environment caused by erection of the structure (e.g. tall building). This study is particularly important to assess the impact of wind on pedestrians, motor vehicles and architectural features such as fountains etc. which utilize public domain within the vicinity of the proposed structure.

- Wind loads for façade - to assess design wind pressures throughout the surface area of the structure for designing the cladding system. Due to the significant cost of typical facade systems in proportion to the overall cost of very tall 
buildings, engineers cannot afford the luxury of conservatism in assessing design wind loads. With due consideration to the complexity of building shapes and dynamic characteristics of the wind and building structures, even the most advanced wind codes generally cannot accurately assess design loads. Wind tunnel testing to assess design loads for cladding,is now normal industry practice, with the aim of minimizing initial capital costs, and more significantly avoiding expensive maintenance costs associated with malfunctions due to leakage and/or structural failure.

\section{CONCLUSION}

This paper has considered a number of key factors associated with the design of tall buildings to the effects of wind loading. The general design requirements for structural strength and serviceability assume particular importance in the case of tall building design as significant dynamic response can result from both buffeting and cross-wind wind loading excitation mechanisms. Serviceability with respect to occupier perception of lateral vibration response can become the governing design issue necessitating the introduction of purpose-designed damping systems in order to reduce these vibrations to acceptable levels. Dynamic response levels also play an important role in the detailed design of façade systems. State of the art boundary layer wind tunnel testing, for determining global and local force coefficients and the effects of wind directionality, topographical features and nearby structures on structural response, is recognized as being particularly useful to tall building design. The emerging use of CFD codes, particularly at the concept design stage, is also noted as assuming increasing importance in the design of tall buildings.

\section{REFERENCES}

[1] Hira A. and Mendis P. (1995) Wind Design of Tall Buildings. Conference on High-rise Buildings in Vietnam. Hanoi, Vietnam, February Irwin A.W. (1978) Human Response to Dynamics Motion of Structures. The Structural Engineer London. Deaves D.M., Harris, R.I. (1978) A mathematical model of the structure of strong winds. Report No. 76. United Kingdom

[2] Construction Industry Research and Information Association. Melbourne W.H. (1989) Private Communication. Taranath B.S. (1988) Structural Analysis and Design of Tall Buildings. McGraw-Hill Book Company. Yamada M. and Goto (1975). T. The criteria to motions in Tall Buildings. Proc. Pan Pacific Tall Buildings Conference, Hawaii, pp. 233-244. Holmes D.J. 2001. Wind Loading of Structures. Spon Press, London Sachs P. 1978. Wind Forces in Engineering, Pergamon Press,

[3] Oxford Davenport, A.G. (1967) The dependence of wind loads on meteorological parameters. Proc. Int. Res. Seminar, Wind Effects on Buildings and Structures, Ottawa, Univ. of Toronto Press, $19-82$

[4] AS/NZ1170.2 (2002) Australian/New Zealand Standard, Structural design actions, Part 2: wind actions, Standards Australia \& Standards New Zealand. Tamura Y., Ohkuma, T., Okada, H., Kanda, J. (1999) Wind loading standards and design criteria in Japan, $J$. Wind

[5] Engineering and Industrial Aerodynamics, 83, 1, 555-566. Cooney R.C. and King, A.B. (1988) Serviceability criteria of buildings ANSI Code (1982). ANSIA58.1-1982. Minimum Design Loads for Buildings and Other Structures. Indian NationalStandards Institute Soong T.T. and Costantinou, M.C. (1994). Passive and active structural vibration control in civil engineering. 